\title{
Rapid eye movement sleep time in dairy cows changes during the lactation cycle
}

\author{
Emma Ternman, ${ }^{1 *}$ Emma Nilsson, ${ }^{2}$ Per Peetz Nielsen, ${ }^{3}$ Matti Pastell, ${ }^{4}$ Laura Hänninen, ${ }^{5}$ and Sigrid Agenäs ${ }^{2}$ \\ ${ }^{1}$ Department of Animal Science, Aarhus University, Blichers Allé 20, PO Box 50, DK-8830 Tjele, Denmark \\ ${ }^{2}$ Department of Animal Nutrition and Management, Swedish University of Agricultural Sciences, Box 7024, 750 07 Uppsala, Sweden \\ ${ }^{3}$ Department of Large Animal Sciences, University of Copenhagen, Grønnegårdsvej 8, 1870 Fredriksbjerg C, Denmark \\ ${ }^{4}$ Natural Resources Institute Finland (Luke), Production Systems, Latokartanonkaari 9, 00790 Helsinki, Finland \\ ${ }^{5}$ Production Animal Medicine and Research Centre for Animal Welfare, University of Helsinki, Koetilantie 2, 00014 Helsinki, Finland
}

\section{ABSTRACT}

The importance of rest and sleep is well established; we know, for example, that lack of sleep impairs immune function in rats and increases pain sensitivity in humans. However, little is known about sleep in dairy cows, but a lack of rest and sleep is discussed as a possible welfare problem in cattle. A first step toward a better understanding of sleep in dairy cows is to quantify the time cows spend awake and asleep in different stages of lactation. Using electrophysiological recordings on 7 occasions in wk $-2,2,7,13,22,37$, and 45 in relation to calving, we investigated changes in rapid eye movement (REM) sleep time as well as non-rapid eye movement (NREM) sleep, drowsing, awake, and rumination in 19 dairy cows of the Swedish Red breed kept in single pens with ad libitum access to feed and water. The recordings on wk -2 and 45 were conducted during the dry period, and all others during lactation. The PROC MIXED procedure in SAS (SAS Institute Inc., Cary, NC) was used to test for significant differences in REM, NREM, drowsing, awake, and rumination between the different stages of lactation cycle. Pairwise comparisons between all recording occasions showed that total REM sleep duration was shorter for cows in wk 2 relative to calving compared with wk -2 , and the number of REM sleep bouts were fewer in wk 2 compared with wk -2 . The REM sleep was recorded during both the day (0500-2100 h) and night (2100-0500 h), but predominantly performed at night compared with daytime, and the bout duration was longer during nighttime compared with daytime. A tendency was observed for time spent in NREM sleep to be shorter in wk 2 relative to calving compared with

Received November 6, 2018.

Accepted February 8, 2019.

*Corresponding author: Emma.Ternman@anis.au.dk wk -2 . The duration spent drowsing was shorter for cows in wk 2 and 13 relative to calving compared with wk -2 . We found no effect of stage of lactation cycle on the duration of awake or ruminating. Our study is the first to assess sleep distribution during a lactation cycle, and our results show that stage of lactation is important to consider when moving forward with sleep investigations in dairy cows. The shortest REM sleep duration was found for cows 2 wk after calving and longest $2 \mathrm{wk}$ before calving, and the difference was due a higher number of REM sleep bouts in the recording 2 wk before calving. The REM sleep and rumination predominantly occurred at night but were recorded during both day and night.

Key words: dairy cow, lactation cycle, rapid eye movement sleep, filter

\section{INTRODUCTION}

Common welfare problems in dairy herds include lameness, mastitis, and decreased longevity due to impaired fertility (EFSA, 2009). In the report by EFSA (2009), it is also stated that "A reduction in lying time due to poor housing is likely to have a more severe effect on animal welfare if the time spent sleeping is reduced." It is known from previous research in rats that lack of sleep affects the endocrine system, impairs immune function, and increases energy expenditure, and that sleep deprivation in humans increases pain sensitivity (Bergmann et al., 1989; Everson, 1995; Moldofsky, 2001; Bonnet, 2005). The high energy turnover in lactating dairy cows makes sleep requirements particularly interesting.

The time budgets of dairy cows include time-consuming activities such as eating, lying, and being milked, as well as time spent moving between these activities. In loose housing systems, cows spend $4 \mathrm{~h}$ on feed intake (Gomez and Cook, 2010), rumination accounts for $7 \mathrm{~h}$ (Dado and Allen, 1994), and cows lie down for 10 to $12 \mathrm{~h}$ per 24-h period (DeVries et al., 2011; Deming et 
Table 1. Mean and SD for stage of lactation cycle (weeks relative to calving), number of cows per recording, milk yield per recording (kg), and total recording time per cow (min)

\begin{tabular}{lcccc}
\hline Stage of lactation cycle & $\begin{array}{c}\text { Weeks relative to calving } \\
{[\text { mean (SD)] }}\end{array}$ & $\begin{array}{c}\text { No. of } \\
\text { cows }\end{array}$ & $\begin{array}{c}\text { Milk yield } \\
{[\mathrm{kg} ; \text { mean (SD)] }}\end{array}$ & $\begin{array}{c}\text { Average recording time per cow } \\
{[\text { min; mean (SD)] }}\end{array}$ \\
\hline Late dry period & $-2.0(0.72)$ & 19 & $0(0)$ & $1,396(100.3)$ \\
Early lactation & $2.2(0.41)$ & 19 & $34.5(5.8)$ & $1,439(0.5)$ \\
Peak lactation & $7.0(0.78)$ & 19 & $41.4(6.2)$ & $1,423(42.5)$ \\
Post-peak lactation & $13.0(0.74)$ & 19 & $41.0(7.2)$ & $1,439(0.5)$ \\
Mid lactation & $21.8(0.52)$ & 19 & $34.7(8.0)$ & $1,435(13.4)$ \\
Late lactation & $37.0(1.75)$ & 19 & $22.1(9.4)$ & $1,413(64.3)$ \\
Early dry period & $45.5(3.26)$ & $18(0)$ & $1,404(92.3)$ \\
\hline
\end{tabular}

al., 2013; Helmreich et al., 2014). The time budget for lactating cows also includes time for milking and waiting to be milked (Helmreich et al., 2014). It is possible that the sum of all these activities causes a conflict in the time budget, compromising the time for resting and sleeping.

A first step toward a better understanding of sleep in dairy cows is to quantify the time cows spend awake and asleep in different stages of lactation when given the possibility to rest and sleep without losing time moving between and waiting for feed, water, milking, and access to a place to lie down. Previous research on sleep in dairy cows that used chronically implanted electrodes for electrophysiological recordings of brain activity concluded that cows sleep lying down approximately $4 \mathrm{~h}$ per $24 \mathrm{~h}$ and only during nighttime (Ruckebusch, 1972). However, only a few cows were included in the previous studies and factors that could be of importance for the need of and time for sleep, such as milk yield, stage of lactation, and pregnancy were not reported (Ruckebusch, 1972). The need for sleep in today's high-yielding dairy cows during lactation and dry period is not known. The invasive method for sleep recording used by Ruckebusch (1972) meant that the cows were restricted in movement, which may have interfered with their sleeping behavior. Our research group developed a noninvasive method for estimating sleep in dairy cows (Ternman et al., 2012) and used this method to evaluate day-to-day variations in sleep time (Ternman et al., 2018). The noninvasive method allows us to accurately record total time for rapid eye movement (REM) sleep, the only vigilance state in which the cow cannot ruminate, and the method also generates accurate data on total rumination time. Other vigilance states that can be distinguished when the cow is not ruminating are awake, drowsing, and non-rapid eye movement (NREM) sleep. The constant chewing during rumination causes artifacts in the data, and it is therefore not possible to identify a vigilance state during rumination. Attempts have been made to produce a filter removing these artifacts, and although the outcome looks promising (Pastell et al., 2012), the method needs further validation before it can be readily used.

The aim of this study was thus to investigate how REM sleep time per day changes during the course of late dry period, one lactation period, and early next dry period in dairy cows kept in single pens with ad libitum access to feed and water. In addition, rumination time and the vigilance states when not ruminating (NREM sleep, drowsing, and awake) were also scored.

\section{MATERIALS AND METHODS}

All animal handling was approved by the Uppsala Local Ethics Committee (Ref. C290/12 and C75/13), Sweden.

\section{Experimental Design, Animals, and Management}

The study involved electrophysiological recordings of rumination, wakefulness, drowsing, and NREM and REM sleep in 19 dairy cows of the Swedish Red Breed during seven 24-h recording sessions within the late dry period, one lactation period, and early next dry period, referred to as one lactation cycle (Table 1 ).

All cows belonged to the research herd at the Swedish University of Agricultural Sciences, Uppsala, Sweden. Recordings were carried out from June 2010 to December 2011 and from April 2013 to April 2014. The research herd was moved to new facilities at another farm between the 2 periods, but the cows were managed similarly during the recording sessions at the 2 farms. Eight cows were recorded at the old facility (farm 1) and 11 cows at the new facility (farm 2). At farm 1, the housing systems were tiestall with milking twice daily and a loose housing system with a voluntary milking system (DeLaval International AB, Tumba, Sweden), and cows would frequently move between the compartments as needed by various research projects. Farm 2 had both a voluntary milking system and an automatic milking rotary system (DeLaval International AB). All 
cows in the research herd were accustomed to the different housing and milking systems, as they were moved between systems depending on stage of lactation and ongoing research. The mean (SD) age of the cows were 56 (18) mo at the start of the study, and the mean (SD) lactation number was 3.3 (1.5) during the study. Mean (SD) milk yield for the 5 recordings during lactation was 34.0 (10.2) $\mathrm{kg}$ and the last recording was made 28.7 (8.0) d after drying off. Three of the 19 cows did not become pregnant again during the lactation period and the other 16 had 117.1 (30.5) d open after calving and were 207 (36.5) d pregnant at the recording during the early dry period, which was the last recording occasion.

From $2 \mathrm{~d}$ before and during each 24 -h recording session, the cows were kept in individual pens $(3 \times 3 \mathrm{~m})$ with visual and audible contact with conspecifics in adjacent individual pens. The pens were equipped with a feeding trough for silage and concentrate, a pressurevalve water bowl, and milk lines so that cows could be bucket milked twice daily (milking times on farm 1: 0700-0800 h and 1600-1700 h, and farm 2: 0600-0700 $\mathrm{h}$ and $1600-1700 \mathrm{~h}$ ) without leaving the pen. The cows had ad libitum access to water and silage during recording sessions and silage was replaced twice daily. Concentrate was fed according to calculated requirements for maintenance and milk production (Spörndly, 2003). In the early dry period, cows did not receive concentrate. The floor was covered with a rubber mat and bedded daily with at least a 3 -cm layer of wood shavings. Ventilation was mechanical and light hours were from 0700 to $1800 \mathrm{~h}$ at farm 1 and from 0530 to $2030 \mathrm{~h}$ at farm 2. During the rest of the time, a dim night light was provided. Day was defined as 0500 to $2100 \mathrm{~h}$ and night as 2100 to $0500 \mathrm{~h}$ for both farms. Milk yield $(\mathrm{kg})$ was estimated by manually weighing the collected milk for the time the cows were housed in the individual pens, and recorded by the milking systems (DeLaval International AB) when cows were housed in the loose housing and tiestall systems.

\section{Equipment and Recording Method}

The cows were fitted with a harness and a textile halter at a minimum of $36 \mathrm{~h}$ before the recording started and were shaved at the electrode attachment sites to ensure sufficient conduction. The shaved patches were cleaned with alcohol and then adhesive electrodes (Unilect, Unomedical Ltd., Birkerød, Denmark) were secured to the skin with tissue glue (3M Vetbond, St. Paul, MN) just before the recording started. The electrodes $(\varnothing 3 \mathrm{~cm})$ were positioned as shown in Figure 1 (courtesy of Ternman et al., 2012). The electrophysiological recordings were always started in connection to the morning milking and were sampled for $24 \mathrm{~h}$ at
$256 \mathrm{~Hz}$ and stored on the recording device until the recording ended.

\section{Data Handling and Analysis}

The vigilance states NREM, REM, awake, drowsing, and rumination were scored in 30-s intervals as described by Ternman et al. (2012). Analysis of behavioral and electrophysiological data included total time and duration of bouts during the 24-h recording sessions. Duration per vigilance state (min) and the number of bouts for each vigilance state $(\mathrm{min})$ were calculated as a percentage of total recorded duration for day $(16 \mathrm{~h})$ and night $(8 \mathrm{~h})$, respectively. Mean daily milk yield per recording session was calculated by summing the yields from each individual milking during the recording week and dividing it by the total number of milkings for the same week.

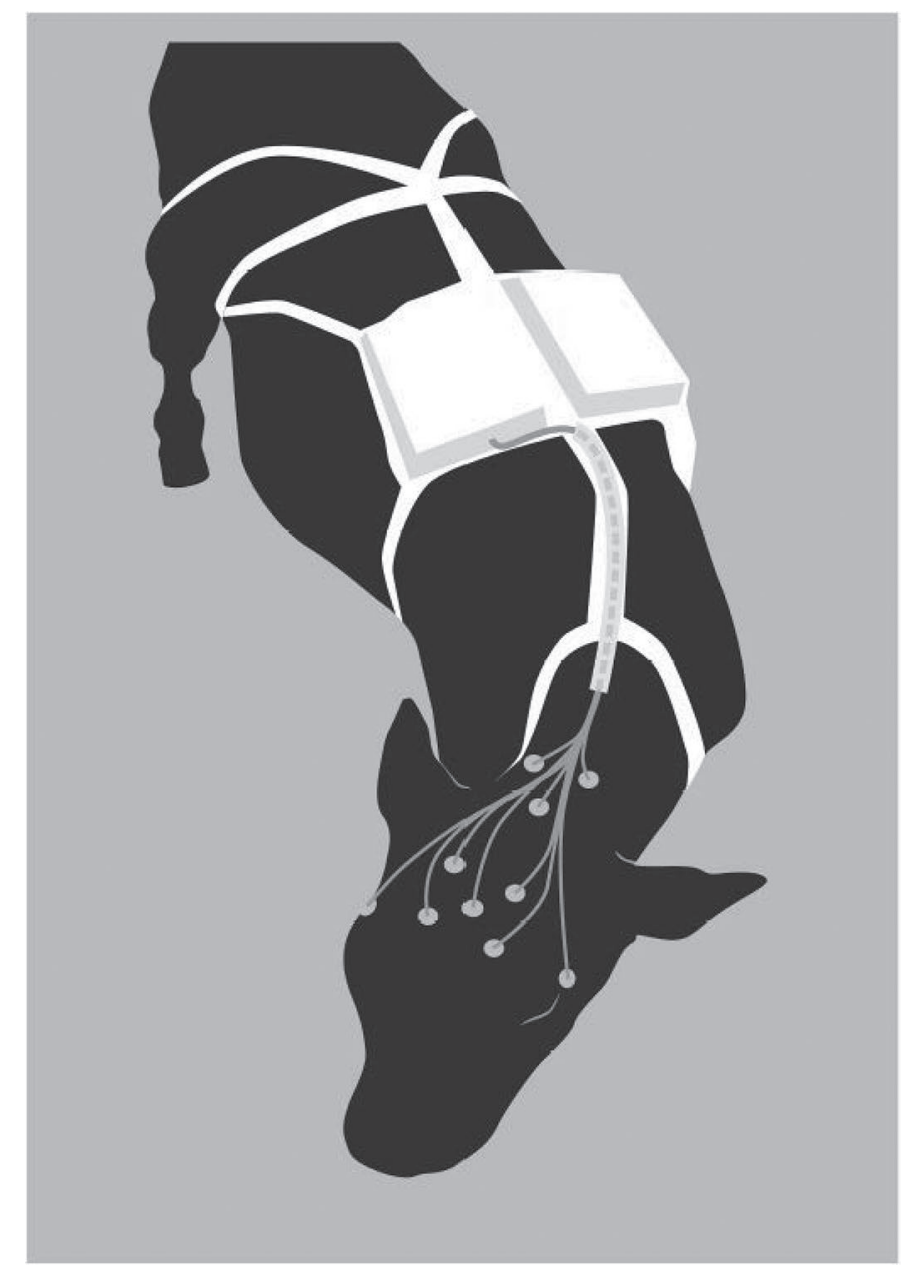

Figure 1. Position of the electrodes and equipment for electrophysiological recordings of vigilance states in dairy cows. Reprinted from Ternman et al. (2012) with permission from Elsevier. 


\section{Statistical Analysis}

The effect of stage of lactation cycle and time of day on sleep and activity was tested with a linear mixed model (SAS 9.4, SAS Institute Inc., Cary, NC). The statistical model included the fixed effects of farm (1 and 2), stage of lactation cycle ( $\mathrm{wk}-2$ relative to calving; lactation wk 2, 7, 13, 21, and 36; and wk 45 relative to calving), and time of day (day or night). In addition, the interaction of stage of lactation cycle and time of day was added when testing for interactions of recording occasion and time of day. Cow nested within farm was included as a random effect using the statement "random cow(farm)." Milk yield did not change significantly between recording occasions and was therefore not included in the model for statistical analyses. For the fixed effects, least squares means were calculated and differences between them were tested for significance using $t$-tests, applying Tukey-Kramer adjustments to avoid overestimation of differences. Normality and equality of variance were checked by visual inspection of the residuals. Values given are mean (SD) or least squares means \pm standard error of the mean.

\section{RESULTS}

Recordings were successfully made for 18 cows on all 7 recording occasions (details shown in Table 1). One cow on farm 1 had a long calving interval and an extended lactation in the trial and did not reach the dry period before the herd moved to farm 2 . She was therefore not included in the final recording. Milk yield was higher on farm 1 than farm $2(37.6 \pm 2.0$ and 32.7 $\pm 1.7 \mathrm{~kg}$, respectively, $P<0.001)$.

\section{Overall Time Spent in the Different Vigilance States and Rumination}

Total duration of REM sleep changed with stage of the lactation cycle $\left(P<0.01 ; \mathrm{F}_{6,107}=3.49\right)$, with shorter total duration for cows in the early lactation $(34.2 \pm 4.38 \mathrm{~min})$ compared with late dry period (50.3 $\pm 4.38 ; P=0.01 ; t=3.45)$. A tendency was observed for the same effect for the total duration of NREM sleep $\left(P=0.06 ; \mathrm{F}_{6,107}=2.08\right)$ with $54.1 \pm 9.55 \mathrm{~min}$ of NREM sleep for cows in early lactation and $86.3 \pm 9.55$ min for cows in the late dry period $(P=0.05 ; t=3.00)$. The total duration of drowsing was affected by stage of lactation cycle $\left(P<0.001 ; \mathrm{F}_{6,107}=4.39\right)$ with shorter duration for cows in early $(37.6 \pm 5.48 \mathrm{~min})$ and postpeak lactation $(41.1 \pm 5.48 \mathrm{~min})$ compared with late dry period $(65.2 \pm 5.48 \mathrm{~min} ; P<0.05 ; t>2.21)$. Farm did not have an effect on any of the registrations of total duration of REM sleep, NREM sleep, or drowsing. We found no effect of stage of lactation cycle or farm on the duration of awake $\left(P=0.1 ; \mathrm{F}_{6,107}=2.28\right.$ and $P$ $=0.60 ; \mathrm{F}_{1,17}=0.40$, respectively $)$ or ruminating $(P=$ $0.10 ; \mathrm{F}_{6.107}=2.60$ and $P=0.24 ; \mathrm{F}_{1,17}=1.23$, respectively). The changes in total duration of REM sleep, NREM sleep, drowsing, awake, and ruminating during the stage of lactation and dry period are illustrated in Figure 2 (supporting material in Appendix Table A1).

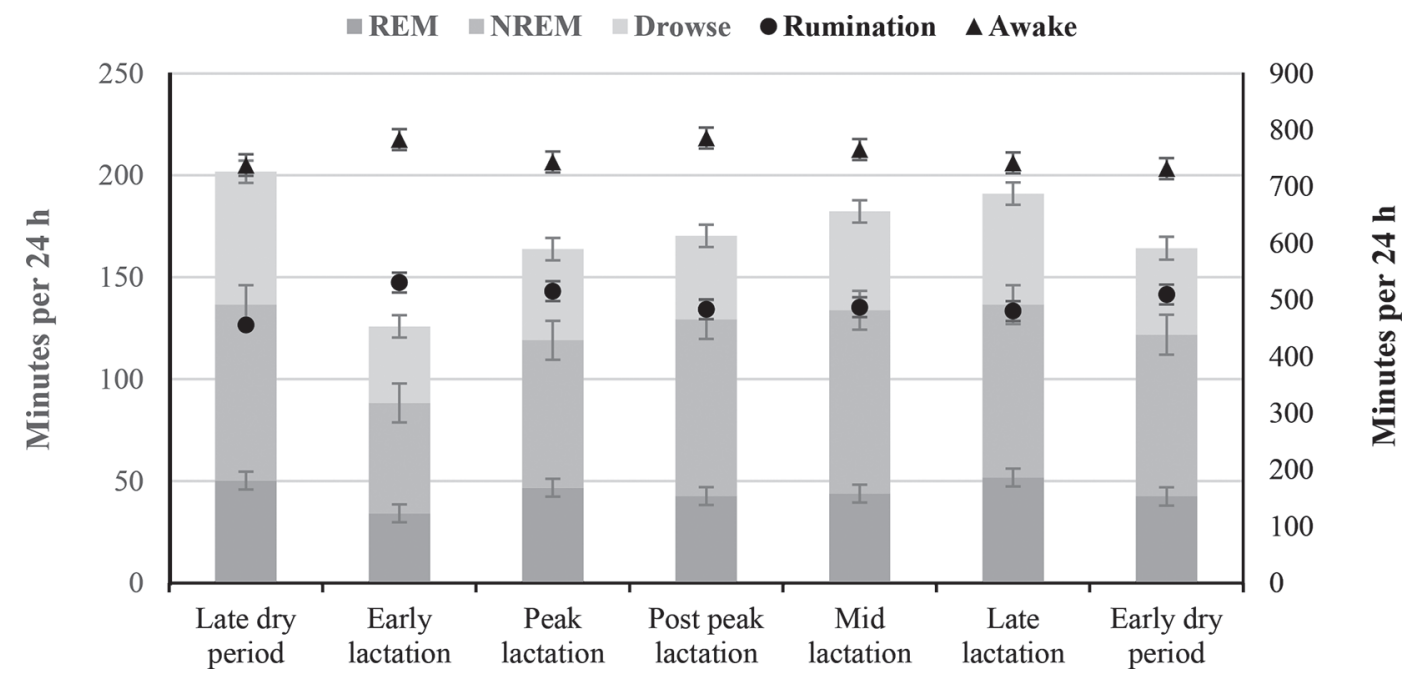

Figure 2. The LSM for total duration of rapid eye movement (REM) sleep, non-rapid eye movement (NREM) sleep, and drowsing (min per $24 \mathrm{~h}$ ) displayed on the left axis, and rumination and awake (min per $24 \mathrm{~h}$ ) displayed on the right axis during the different recording occasions late dry period; early, peak, post-peak, mid, and late lactation; and early dry period, corresponding to wk $-2,2,7,13,22,37$, and 45 relative to calving. Error bars indicate SEM. 


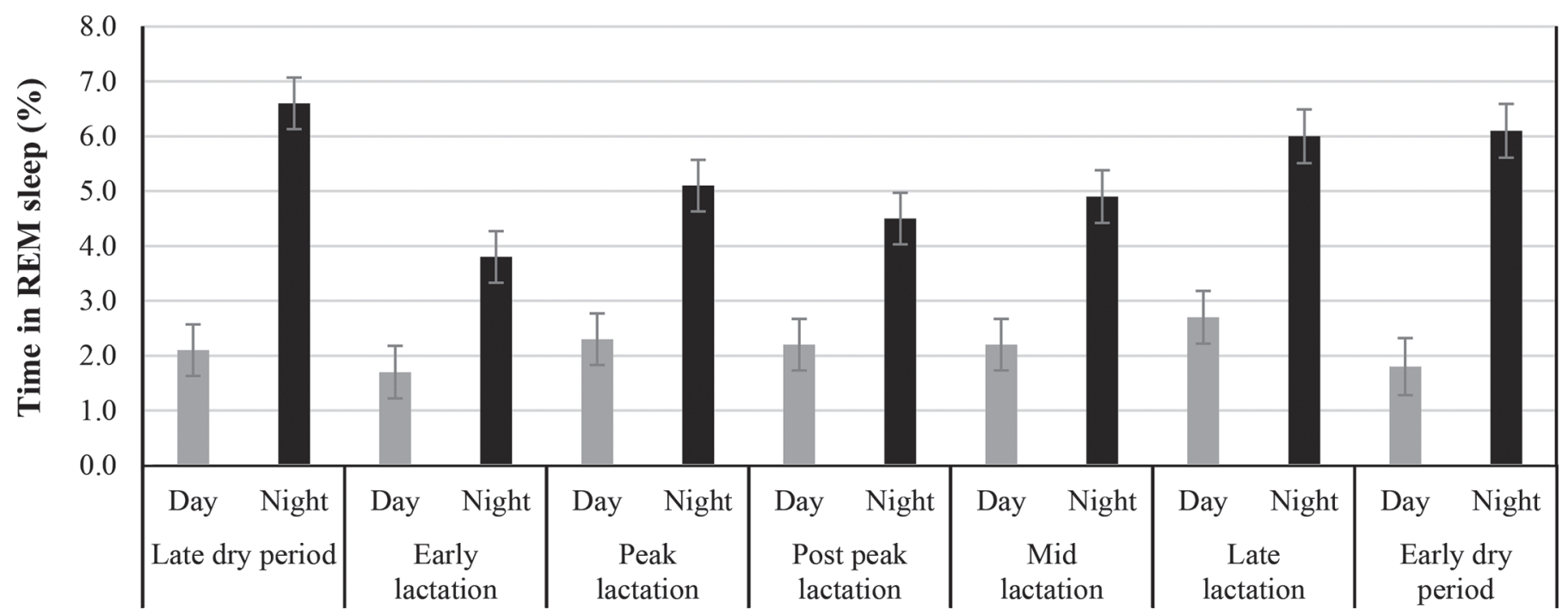

Figure 3. Percent of rapid eye movement (REM) sleep duration of total recorded time during the day and the night for the late dry period; early, peak, post-peak, mid, and late lactation; and early dry period, corresponding to $-2,2,7,13,22,37$, and 45 wk relative to calving. Error bars indicate SEM.

\section{REM Sleep Distribution}

We found an overall effect of stage of lactation and dry period for the duration of REM sleep bouts $(P=$ $0.05 ; \mathrm{F}_{6,107}=2.17$ ), but we could not detect any pairwise differences. The number of REM sleep bouts were affected by stage of lactation cycle $\left(P<0.001 ; \mathrm{F}_{6,107}\right.$ $=5.17)$ and were fewer in early lactation $(7.5 \pm 0.90)$ compared with the late dry period $(12.4 \pm 0.90 ; P<$ $0.001 ; t=5.06)$, and the number of bouts was greater on farm $2(11.7 \pm 0.69)$ compared with farm 1 (9.1 \pm $\left.0.76 ; P<0.05 ; \mathrm{F}_{1,17}=6.64\right)$.

Cows spent a proportionally longer time in REM sleep at night $(5.3 \pm 1.19 \%$ of total nighttime) compared with during the day $(2.1 \pm 1.19 \%$ of total daytime; $P$ $<0.05 ; \mathrm{F}_{1,18}=207.34$; Figure 3$)$. We also found significant pairwise interactions $\left(P<0.01 ; \mathrm{F}_{6,101}=2.25\right)$ with a greater percentage of REM sleep at night during late dry period ( $6.6 \pm 0.47 \%$ of total nighttime) compared with nighttime in early lactation $(3.8 \pm 0.47 \%$ of total nighttime; $P<0.01 ; t=4.25)$. Percentage of REM sleep time during nighttime in early lactation did not differ compared with percentage of REM sleep during daytime for any of the stages of lactation and dry period $(P>0.18)$. A tendency was observed for the proportion of REM sleep bouts to be greater during nighttime $(54.1 \pm 1.80 \%)$ compared with daytime (47.7 $\left.\pm 1.80 \% ; P=0.06 ; \mathrm{F}_{1,18}=3.74\right)$, and we found an interaction effect of time of day and stage of lactation cycle on the percent of bouts for REM sleep $(P<0.01$; $\left.\mathrm{F}_{6,101}=4.06\right)$, including pairwise effects. Fewer REM sleep bouts were observed during daytime in the early dry period $(37.7 \pm 4.28 \%)$ compared with nighttime in the same period $(66.1 \pm 4.01 \% ; P<0.01 ; t=4.00)$, nighttime during the late dry period $(59.7 \pm 4.00 \% ; P$ $<0.05 ; t=3.74)$, and nighttime during early lactation $(57.8 \pm 3.94 \% ; P<0.05 ; t=3.45)$. The percent of REM sleep bouts was greater for nighttime in early dry period $(66.1 \pm 4.01 \%)$ compared with nighttime in mid-lactation $(46.9 \pm 4.00 \% ; P=0.05 ; t=3.41)$.

The bout duration was longer during the nighttime $(4.6 \pm 0.09 \mathrm{~min})$ compared with daytime $(4.1 \pm 0.09$ $\left.\min ; P<0.001 ; \mathrm{F}_{1,18}=17.32\right)$, but no effect was observed of farm on the duration of REM sleep bouts $(P$ $\left.=0.12 ; \mathrm{F}_{1,17}=2.75\right)$.

\section{Rumination}

We found an overall effect of the duration of rumination bouts $\left(P<0.05 ; \mathrm{F}_{6,107}=2.33\right)$ for the stage of lactation and dry period, but no pairwise effects were detected. Cows spent more time ruminating at night $(46.4 \pm 0.66 \%$ of total nighttime) than they did during the day $\left(28.8 \pm 0.66 \%\right.$ of total daytime; $P<0.001 ; \mathrm{F}_{1,18}$ $=593.23)$. Rumination bouts were also longer at night $(34.6 \pm 0.58 \mathrm{~min})$ compared with daytime $(27.4 \pm 0.47$ min; $\left.P<0.001 ; \mathrm{F}_{1,18}=97.30\right)$, and longer at farm 1 $(33.4 \pm 0.61 \mathrm{~min})$ compared with farm $2(29.6 \pm 0.49$ $\left.\min ; P<0.001 ; F={ }_{1,17}=23.16\right)$. The number of rumination bouts was fewer on farm $1(15.9 \pm 0.37)$ compared with farm $2\left(17.0 \pm 0.31 ; P<0.001 ; \mathrm{F}_{1,17}\right.$ $=18.76)$, and the percentage of bouts at night was smaller (38.8 $\pm 0.81 \%$ of total rumination bouts) com- 
pared with daytime $(61.2 \pm 0.81 \%$ of total rumination bouts; $\left.P<0.001 ; \mathrm{F}_{1,18}=204.35\right)$.

\section{DISCUSSION}

Our results show that the duration of sleep changes during lactation and dry period, with the shortest REM sleep duration recorded in early lactation compared with the late dry period. Ruckebusch (1975) also reported this reduction in sleep time after parturition. The results on sleep distribution in our study is in accordance with the distribution of lying time for healthy cows 4 wk before and 4 wk after calving reported by Kok et al. (2017). We did not detect an effect of stage of lactation on the REM sleep duration, although other studies have shown a positive correlation between DIM and lying time (Bewley et al., 2010; Vasseur et al., 2012; Ito et al., 2014; Maselyne et al., 2017). The increased lying time during lactation as shown in other studies has been suggested to be due to an increase in lying bout duration (Nielsen et al., 2000), or an increase in number of lying bouts (Endres and Barberg, 2007). For the recordings during the lactation in our study, no effect of stage of lactation on either the duration or number of REM sleep bouts was detected. The study design may have affected the cows' behavior and prevented them from fully engaging in sleep and rest as they were separated from the herd (Boissy and Le Neindre, 1997). However, because they were housed in a similar way during all the recordings, the differences between recording sessions should still be valid. Sleeping in a new environment might affect sleep duration or sleep distribution; this is known as the first-night effect (Le Bon et al., 2001). The cows in our study had previous experience of the recording environment before entering the study, but due to the study design, there might still have been an effect of the order of the recordings on the sleep duration or distribution (or both) as the cows would become more familiar with the environment throughout the study. There are no long-term studies of sleep habituation in dairy cows, but our previous study on short-term effects on sleep showed no firstnight effect when recorded over a 72-h period (Ternman et al., 2018). A possible habituation over the course of the present study would most likely have increased REM sleep duration from the first recording occasion, whereas our results show the opposite with the longest REM duration on the first recording occasion.

The overall duration of REM sleep per $24 \mathrm{~h}$ is similar to what we previously showed (Ternman et al., 2018). Total REM sleep duration is also similar to the early sleep studies (Ruckebusch, 1972, 1975). However, NREM sleep time in our study was half of the $3 \mathrm{~h} 13$ min reported by Ruckebusch (1972) and drowsing dura- tion in our study was a little less than $1 \mathrm{~h}$, compared with $7 \mathrm{~h}$ reported by Ruckebusch (1972). It is likely that the discrepancy between Ruckebusch (1972) and our study is due to the muscle artifacts during rumination, overriding the other signals in the data. The method used in the studies by Ruckebusch (1972) and Ruckebusch (1975) with implanted electrodes generated reliable data on vigilance state regardless of rumination, but as the method is vastly invasive and requires that the cows are housed tied-up, it might modify the cows' behavior. The development of a validated filter to remove the artifacts caused by muscle contractions in the sleep data, as tested in Pastell et al. (2012), would be a great contribution to the noninvasive sleep studies, but further work and validation of the filtered data are needed. For an accurate development and validation of the filtering method, there is a need for a ground truth (e.g., data recorded from cows with implanted electrodes). Without the filter, we can only rely on the changes in REM sleep, as rumination cannot occur during this state (Ruckebusch et al., 1974; Toutain et al., 1977). During normal mammalian sleep, REM sleep is positively correlated with NREM sleep (Capellini et al., 2008), which means that an increase in REM sleep time might reflect an increased need for NREM sleep too.

The REM sleep was recorded during both day and night, but the larger proportion was performed at nighttime, similar to our findings for cows in Ternman et al. (2018) and for calves in Hänninen et al. (2008). In the earlier study on sleep in dairy cows (Ruckebusch, 1972), all of the REM sleep was recorded during the nighttime. This difference in REM sleep day-night distribution between the studies could be attributable to the recording environment. In our study, cows were housed in individual pens in a quiet part of the barn, with the possibility to move around freely. Due to the nature of the recording method, the cows in the study by Ruckebusch (1972) were confined, which could have made them less inclined to relax at daytime when other activities were ongoing in the barn.

The cows showed proportionally more REM sleep at night within each stage of the lactation cycle, but the percent of REM during the night in early lactation was so small that it did not differ from percent of REM sleep during daytime for any of the other recordings during the lactation cycle. We also found the greatest difference in REM sleep duration and distribution between late dry period and early lactation. Total duration of REM sleep was shorter with fewer REM sleep bouts in early lactation ( 2 wk postpartum) than during other recording points. Cows in early lactation are also known to have shorter total lying time, and shorter lying bouts compared with cows in late dry period (Kaufman et al., 2016b). It has been suggested that this is related to the 
changes in time allocation between dry cows and lactating cows, as lactating cows spend more time standing during milking and more time feeding (Kaufman et al., 2016b). On the other hand, the results by Kok et al. (2017) indicate that the time feeding does not compromise lying time.

Farm affected the duration and number of REM sleep bouts, as well as the duration of rumination bouts, but no effect was observed on total duration for REM sleep or rumination. The daily routines at the 2 farms might have influenced the distribution of the cows' activities but did not necessarily affect their total time performing them, which is in agreement with the study by DeVries and von Keyserlingk (2005) where the time of feeding affected lying distribution but not total lying time. Type and size of resting place, as well as type of bedding material, may also influence lying distribution (Gomez and Cook, 2010; Ito et al., 2014). In our study, the size of the pen and the bedding material were the same for both farms.

Similar to findings on rumination time during the transition period by Kaufman et al. (2016a), we did not detect an effect of stage of the lactation cycle on the total duration of ruminating in our study. The larger proportion of rumination occurred at night in our study, also reported by Schirmann et al. (2012). There is a temporal context between the time for feeding and rumination, which peaks $4 \mathrm{~h}$ after feeding (Schirmann et al., 2012), and the cows in our study were fed several times during the day but only occasionally during the night. We did not record feed intake or feeding time, and because only a weak correlation is present between feed intake and rumination (Schirmann et al., 2012), we cannot estimate if the changes we found for REM sleep time were due to time being allocated to feeding during the early lactation.

\section{CONCLUSIONS}

In conclusion, our results show that stage of lactation is important to consider when moving forward with sleep investigations in dairy cows. The shortest REM sleep duration was found for cows 2 wk after calving and longest 2 wk before calving, and the difference was due a higher number of REM sleep bouts in the recording 2 wk before calving. The REM sleep and rumination predominantly occurred at night but were recorded during both day and night.

\section{ACKNOWLEDGMENTS}

The study was funded by The Swedish Research Council for Environment, Agricultural Sciences and Spatial Planning (Formas, Stockholm, Sweden; project title: Interactions between milk production and the need for sleep in dairy cows, Dnr. 2011-01094).

\section{REFERENCES}

Bergmann, B. M., C. Kushida, C. Everson, M. Gilliland, W. Obermeyer, and A. Rechtschaffen. 1989. Sleep-deprivation in the rat: 2 . Methodology. Sleep 12:5-12.

Bewley, J. M., R. E. Boyce, J. Hockin, L. Munksgaard, S. D. Eicher, M. E. Einstein, and M. M. Schutz. 2010. Influence of milk yield, stage of lactation, and body condition on dairy cattle lying behaviour measured using an automated activity monitoring sensor. J. Dairy Res. 77:1-6.

Boissy, A., and P. Le Neindre. 1997. Behavioral, cardiac and cortisol responses to brief peer separation and reunion in cattle. Physiol. Behav. 61:693-699.

Bonnet, M. 2005. Acute sleep deprivation. Pages 51-66 in Principles and Practice of Sleep Medicine. M. H. Kryger, T. Roth, and W. C. Dement, ed. Elsevier Saunders, Philadelphia, PA.

Capellini, I., R. A. Barton, P. McNamara, B. T. Preston, and C. L. Nunn. 2008. Phylogenetic analysis of the ecology and evolution of mammalian sleep. Evolution 62:1764-1776.

Dado, R. G., and M. S. Allen. 1994. Variation in and relationships among feeding, chewing, and drinking variables for lactating dairy cows. J. Dairy Sci. 77:132-144.

Deming, J. A., R. Bergeron, K. E. Leslie, and T. J. DeVries. 2013. Associations of housing, management, milking activity, and standing and lying behavior of dairy cows milked in automatic systems. J. Dairy Sci. 96:344-351.

DeVries, T. J., J. A. Deming, J. Rodenburg, G. Seguin, K. E. Leslie, and H. W. Barkema. 2011. Association of standing and lying behavior patterns and incidence of intramammary infection in dairy cows milked with an automatic milking system. J. Dairy Sci. 94:3845-3855.

DeVries, T. J., and M. A. G. von Keyserlingk. 2005. Time of feed delivery affects the feeding and lying patterns of dairy cows. J. Dairy Sci. 88:625-631.

EFSA. 2009. Scientific report on the effects of farming systems on dairy cow welfare and disease. EFSA J. 7:1143r.

Endres, M. I., and A. E. Barberg. 2007. Behavior of dairy cows in an alternative bedded-pack housing system. J. Dairy Sci. 90:41924200 .

Everson, C. A. 1995. Functional consequences of sustained sleep-deprivation in the rat. Behav. Brain Res. 69:43-54.

Gomez, A., and N. B. Cook. 2010. Time budgets of lactating dairy cattle in commercial freestall herds. J. Dairy Sci. 93:5772-5781.

Hänninen, L., J. Makela, J. Rushen, A. de Passille, and H. Saloniemi 2008. Assessing sleep state in calves through electrophysiological and behavioural recordings: A preliminary study. Appl. Anim. Behav. Sci. 111:235-250.

Helmreich, S., R. Hauser, T. Jungbluth, B. Wechsler, and L. Gygax. 2014. Time-budget constraints for cows with high milking frequency on farms with automatic milking systems. Livest. Sci. $167: 315-322$.

Ito, K., N. Chapinal, D. M. Weary, and M. A. G. von Keyserlingk. 2014. Associations between herd-level factors and lying behavior of freestall-housed dairy cows. J. Dairy Sci. 97:2081-2089.

Kaufman, E. I., S. J. LeBlanc, B. W. McBride, T. F. Duffield, and T. J. DeVries. 2016a. Association of rumination time with subclinical ketosis in transition dairy cows. J. Dairy Sci. 99:5604-5618.

Kaufman, E. I., S. J. LeBlanc, B. W. McBride, T. F. Duffield, and T. J. DeVries. 2016b. Short communication: Association of lying behavior and subclinical ketosis in transition dairy cows. J. Dairy Sci. 99:7473-7480.

Kok, A., R. J. van Hoeij, B. J. Tolkamp, M. J. Haskell, A. T. M. van Knegsel, I. J. M. de Boer, and E. A. M. Bokkers. 2017. Behavioural adaptation to a short or no dry period with associated management in dairy cows. Appl. Anim. Behav. Sci. 186:7-15.

Le Bon, O., L. Staner, G. Hoffmann, M. Dramaix, I. San Sebastian, J. R. Murphy, M. Kentos, I. Pelc, and P. Linkowski. 2001. The 
first-night effect may last more than one night. J. Psychiatr. Res. $35: 165-172$.

Maselyne, J., M. Pastell, P. T. Thomsen, V. M. Thorup, L. Hänninen, J. Vangeyte, A. Van Nuffel, and L. Munksgaard. 2017. Daily lying time, motion index and step frequency in dairy cows change throughout lactation. Res. Vet. Sci. 110:1-3.

Moldofsky, H. 2001. Sleep and pain. Sleep Med. Rev. 5:385-396.

Nielsen, B., R. Veerkamp, and A. Lawrence. 2000. Effects of genotype, feed type and lactational stage on the time budget of dairy cows. Acta Agric. Scand. A Anim. Sci. 50:272-278.

Pastell, M., E. Ternman, P. P. Nielsen, S. Agenas, and L. Hänninen. 2012. Adaptive filter for denoising cow's EEG measurements based on EMG signal. In Proc. Infomation Technology, Automation and Precision Farming. International Conference of Agricultural Engineering-CIGR-AgEng 2012: Agriculture and Engineering for a Healthier Life, Valencia, Spain, 8-12 July 2012. CIGR-EurAgEng.

Ruckebusch, Y. 1972. Relevance of drowsiness in circadian cycle of farm animals. Anim. Behav. 20:637-643.

Ruckebusch, Y. 1975. Feeding and sleep patterns of cows prior to and post parturition. Appl. Anim. Ethol. 1:283-292.

Ruckebusch, Y., R. Dougherty, and H. Cook. 1974. Jaw movements and rumen motility as criteria for measurement of deep sleep in cattle. Am. J. Vet. Res. 35:1309-1312.

Schirmann, K., N. Chapinal, D. M. Weary, W. Heuwieser, and M. A. von Keyserlingk. 2012. Rumination and its relationship to feeding and lying behavior in Holstein dairy cows. J. Dairy Sci. 95:32123217.

Spörndly, R. 2003. Fodertabeller för idisslare 2003. R. Spörndly, ed. Swedish University of Agricultural Sciences, Uppsala, Sweden.

Ternman, E., L. Hänninen, M. Pastell, S. Agenäs, and P. P. Nielsen. 2012. Sleep in dairy cows recorded with a non-invasive EEG technique. Appl. Anim. Behav. Sci. 140:25-32.

Ternman, E., M. Pastell, L. Hänninen, S. Agenäs, and P. P. Nielsen. 2018. First-night effect on sleep time in dairy cows. PLoS One 13:e0195593.

Toutain, P.-L., C. Toutain, A. J. F. Webstert, and J. D. Mcdonald. 1977. Sleep and activity, age and fatness, and the energy expenditure of confined sheep. Br. J. Nutr. 38:445-454.

Vasseur, E., J. Rushen, D. B. Haley, and A. M. de Passille. 2012. Sampling cows to assess lying time for on-farm animal welfare assessment. J. Dairy Sci. 95:4968-4977.

\section{APPENDIX}

Supporting information for Figure 2 showing the total duration of REM sleep, NREM sleep, drowsing, awake, and rumination during the different recording sessions late dry period; early, peak, post-peak, mid, and late lactation; and early dry period (Table A1).

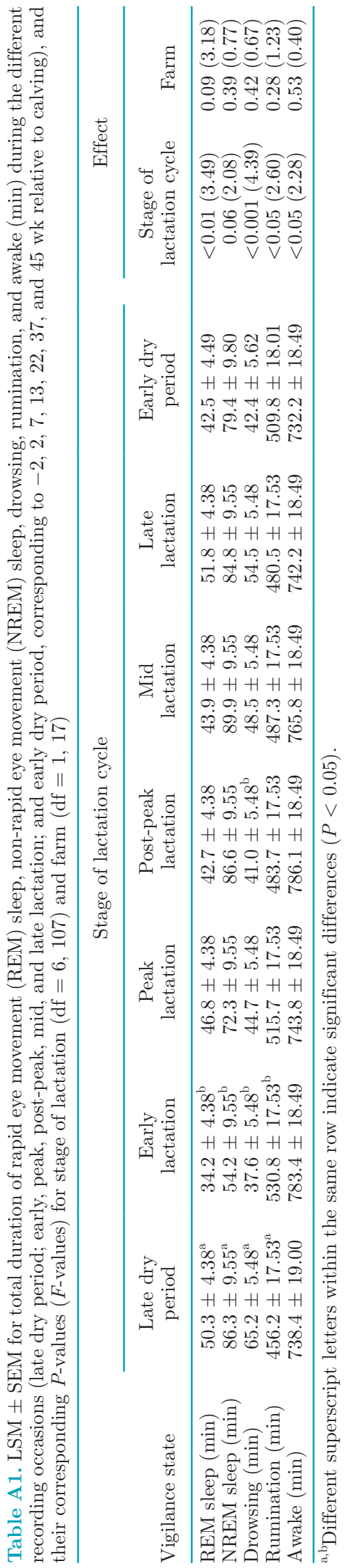

Journal of Dairy Science Vol. 102 No. 6, 2019 